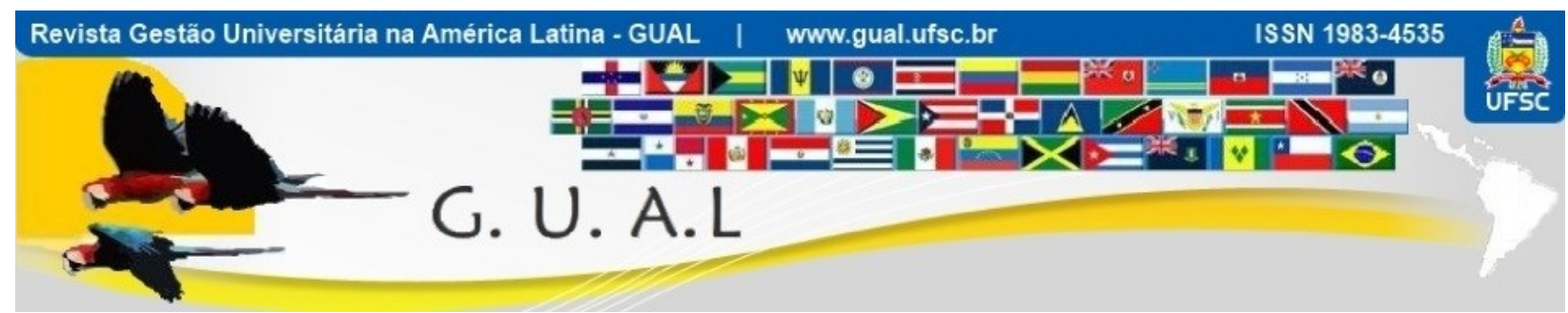

DOI: http://dx.doi.org/10.5007/1983-4535.2015v8n4p189

\title{
SISTEMAS DE INFORMAÇÃO: UM ESTUDO DE CASO EM UMA UNIDADE SUPLEMENTAR DA UNIVERSIDADE FEDERAL DO RIO GRANDE DO NORTE
}

\author{
INFORMATION SYSTEMS: A CASE STUDY WITHIN AN ADDITIONAL UNIT AT \\ THE FEDERAL UNIVERSITY OF RIO GRANDE DO NORTE
}

Karoline Isabelle de Almeida Pereira, Graduada Universidade Federal do Rio Grande do Norte - UFRN karolineisabelle2@.gmail.com

Ilmara Pinheiro Limão, Graduada Universidade Federal do Rio Grande do Norte - UFRN mara.gdj@gmail.com

Paula Flaviane Pinheiro do Nascimento, Graduanda Universidade Federal do Rio Grande do Norte - UFRN paulinha_f.f@hotmail.com

Lenuzia Santos do Nascimento, Graduanda Universidade Federal do Rio Grande do Norte - UFRN lenuzia14@,hotmail.com

Mariane Cristina Lima de Souza, Graduanda Universidade Federal do Rio Grande do Norte - UFRN marianecristina21@,hotmail.com

Recebido em 05/dezembro/2014

Aprovado em 05/abril/2015

Sistema de Avaliação: Double Blind Review

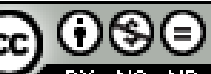

Esta obra está sob uma Licença Creative Commons Atribuição-Uso. 


\title{
RESUMO
}

Este estudo tem como objetivo explanar as contribuições que os sistemas de informações podem oferecer nas tomadas de decisão dentro de uma unidade suplementar na Universidade Federal do Rio Grande do Norte (UFRN) que atua na formação de pessoas na área de tecnologia da informação, desde o nível técnico à pós-graduação. Para demonstrar os benefícios dos sistemas de informação, o artigo baseou-se na pesquisa descritiva e exploratória. O cenário do Instituto foi analisado, através de visitas in loco, previamente, ou seja, antes da implementação do plano gerencial apresentado e posteriormente. Por meio das avaliações pré e pós sistemas de informação, foi possível comparar os resultados e assim identificar claramente o quão importante pode ser a inserção desse tipo de gerenciamento. Foi possível concluir também, como estes podem contribuir positivamente para o processo de tomada de decisões na empresa entre outros benefícios como maior agilidade no processo, maior interação entre as pessoas e mais alguns discutidos ao longo deste trabalho.

Palavras-chave: Sistema de Informação. Plano Gerencial. Tecnologia da Informação.

\begin{abstract}
This study aims to explain the contributions that information systems can provide for making decision within an additional unit at the Federal University of Rio Grande do Norte (FURN), engaged in training people in the field of information technology, from the technical level for postgraduate. To demonstrate the benefits of information systems, the article was based on descriptive and exploratory research. The scenario of the Institute was analyzed previously, namely, before the implementation of the suggested management plan, and after the event. Through avaliation pre and post information systems, it was possible to compare the results and thereby clearly identify how important may be the inclusion of this type of management. Also realize, how these systems can contribute positively to the process of decision making, like other benefits such as greater agility in the process, greater interaction among people and a few more points discussed throughout this work.
\end{abstract}

Keywords: Information System. Business Plan. Information Technology. 


\section{INTRODUÇÃO}

O avanço da tecnologia figurou a ampliação de diversos caminhos, inclusive o da gestão. Através de programas, softwares e outros recursos desenvolvidos, a administração de empresas foi facilitada. A tecnologia da informação começou então a alterar, de forma positiva a forma de administração, afetando de maneira contundente os resultados possíveis de serem alcançados. No entanto, mesmo com todo o progresso diversas organizações não fazem uso dessas ferramentas, ou não as utilizam em sua plenitude, tendo assim resultados aquém do desejado, com perdas significativas que influenciam toda a cadeia produtiva.

De acordo com Finger (1997) os processos de gestão universitária devem ser inovadores e otimizar a interação entre alunos, docentes, funcionário e em geral, toda a comunidade envolvida na cadeia interna e externamente. Dadas as exigências de mercado no que concernente à competitividade, agilidade, flexibilidade e qualidade de informação, as organizações buscam gradativamente mais apoio na utilização de sistemas de informações, para tomada de decisões estratégicas. As instituições universitárias brasileiras, neste contexto, também deveriam fazer uso das mesmas ferramentas para fundamentar suas decisões.

Existe uma ampla gama de pesquisas que objetivam identificar realizações e experiências em instituições acadêmicas, acerca da gestão da informação e sua adequabilidade às necessidades destas instituições. Principalmente no serviço público, predomina a carência de cultura gerencial, trabalhadores sem qualificação para lidar com determinadas tecnologias, falta de indicadores de desempenho e expectativa de maior produtividade e qualidade.

Conforme Rubinsztejn e Palacios (2010) a procura das instituições acadêmicas por melhores formas de gerir as informações, justifica-se para compreender de que forma a construção de de qualidade no serviço é primordial na gestão de serviços educacionais. Como toda gestão serve pra otimizar seus processos internos e assim proporcionar um produto de qualidade e a maior satisfação ao cliente, no meio educacional não é diferente. Objetiva-se uma melhoria interna, para isso os processos são geridos. Estas melhorias resultam em um produto final de maior qualidade, ou seja, um aluno qualificado e mais preparado para o mercado, onde assim irá cumprir função a qual ele foi designado e promover a satisfação do cliente que é a sociedade em que ele está inserido.

O sucesso ou fracasso da implantação de Sistemas de Informações, estão intimamente relacionados contexto da organização na qual eles serão utilizados e na consequente 
formulação de um ambiente adequado, capaz de assegurar o desenvolvimento, a implementação, a aceitação e o uso desse novo sistema. Todo esse processo precisa passar por todas as pessoas envolvidas na organização e na estratégia que será utilizada para garantir o sucesso do mesmo. Desta feita, o desenvolvimento e a implantação de um sistema de informação, não são meras instalação e treinamento de usuários mas sim ações analisadas minuciosamente para um resultado satisfatório.

O artigo está estruturado em 6 seções. Além desta sessão introdutória que apresenta a estrutura do artigo; A seção 2 apresenta a fundamentação teória e subdivide-se em 2 subseções; A seção 3 aborda a metodologia utilizada neste trabalho; A seção 4 fala do estudo de caso de uma unidade suplementar da UFRN; A seção 5 fala dos resultados alcançados com esta pesquisa. Por fim a seção 6 trata das considerações finais deste trabalho.

\section{FUNDAMENTAÇÃO TEÓRICA}

\subsection{SISTEMAS DE INFORMAÇÃO}

Os sistemas de informação possuem informações sobre pessoas, ambientes e elementos externos e internos à organização. Assim, afirma-se que dados são sucessões de fatos não lapidados e informação são dados organizados e ordenados de forma que signifiquem algo para o receptor. Outrora os sistemas foram utilizados especificamente para o processamento das informações operacionais. Atualmente eles passaram a analisar e controlar as informações operacionais, permitindo o gerenciamento da informação, utilizando-as para planejar e apoiar o gerenciamento estratégico.

Cautela e Polloni (1991) afirmam que, Sistema de Informação é um conjunto de elementos interdependentes (subsistemas), logicamente associados, para que, de sua interação, sejam geradas informações úteis, necessárias à tomada de decisões. As informações propiciadas pelo sistema de informação devem ser cercadas de qualidades ou atributos, a saber: ser claras, precisas, rápidas e dirigidas.

Rezende e Abreu (2003) definem um Sistema de Informação como o processo de transformação de dados em informações, utilizadas na estrutura decisória da empresa e que proporcionam a sustentação administrativa, visando à otimização dos resultados esperados

Através dessas definições, observa-se a importância dos Sistemas de Informação no ambiente empresarial atual. Sua existência passa a ser um recurso estratégico primordial na obtenção e manutenção das vantagens competitivas. 


\subsection{SISTEMAS DE INFORMAÇÃO E GESTÃO ACADÊMICA}

Aubertin (1996) afirma que as instituições de ensino deveriam ter a preocupação de ser como as empresas. À medida que o produto delas é o ensino, deveriam preocupar-se com a qualificação dos alunos.

As instituições de ensino, tal qual as demais organizações, devem proveitar os benefícios que a tecnologia oferece. Para aproveitar estas oportunidades, precisa-se abandonar velhas fórmulas de como se fazem as coisas e aderir ao novo, fazendo uso de ferramentas e recursos tecnológicos.

Para o Conselho de Reitores das universidades brasileiras - CRUB (1986), as universidades brasileiras precisam contar com sistemas de informações para promover sua modernização administrativa. Os sistemas de informação devem proporcionar às universidades um embasamento quantitativo e qualitativo nos seus planejamentos, nos processos de tomada de decisão e no estabelecimento das atividades no plano operativo.

\section{METODOLOGIA}

O artigo foi baseado na pesquisa do tipo descritiva. Para Gil (2002) é a descrição das características de determinada população ou fenômeno, ou então, o estabelecimento de relações entre variáveis. Assim, foi necessário ater-se à detalhes para uma melhor definição dos processos da empresa e por conseguinte os pontos passíveis de melhoria. Também pode ser classificada como aplicada, pois a proposta é a resolução de um problema concreto, gerenciar as informações que compõem o setor analisado.

Inicialmente foi definido o objetivo de estudo, no caso, a implementação de sistemas de informação na unidade suplementar. Depois de definido o objetivo, foi desenvolvido uma análise do problema, com auxilio de fluxogramas, desenvolvido no visio, e realizada uma identificação das deficiencias.

O procedimento adotado foi à visita in loco, com observações diretas e conversas informais com os funcionários e a gerência do instituto, assim como mapeamento dos processos do mesmo. Com isso, os dados necessários para o desenvolvimento e aplicação de sistemas de informação, mais adequados a realidade observada na unidade, foram conseguidos. Um questionário semi-estruturado também foi aplicado para os funcionários afim de dimensionar os impactos da implementação do sistema de informação na empresa. 
Quanto aos procedimentos técnicos, foi realizada pesquisa exploratória, poisi acordo com Gil (2002) não é viável restringir-se a um levantamento bibliográfico no intuito de tornar o problema explícito e construir hipóteses. Com base nisso, foram utilizados informações pertinentes ao tema, consulta em artigos e livros relacionados ao exposto no trabalho.

\section{ESTUDO DE CASO: INSTITUTO METRÓPOLE DIGITAL}

O Instituto Metrópole Digital (IMD) é uma Unidade Suplementar da Universidade Federal do Rio Grande do Norte (UFRN), que atua na formação de pessoal de nível técnico, superior e na pós-graduação, cujas ações integram a inclusão social e digital de jovens do ensino básico até a pós-graduação. Contando atualmente com duas unidades físicas. Este trabalho tem como foco o Centro Integrado de Vocação Tecnológica (CIVT), com área total de $8.033,73 \mathrm{~m}^{2}$, onde funcionam a administração do Instituto e os cursos técnicos, de graduação e pós-graduação, mais especificamente o setor pedagógico e conta com cerca de 120 colaboradores.

O setor pedagógico possui integração direta com outros setores, como diagramação, produção de vídeos, revisão, suporte técnico, secretaria, psicologia e corpo docente, fazendose necessária a comunicação com estes para que as demandas auferidas ao setor sejam cumpridas da forma desejada. Eles são responsáveis basicamente por validar o material distribuído aos alunos e garantir a interação entre coordenação-aluno

A empresa, apesar de tratar o ramo de tecnologia da informação, trabalhar com um número considerável de pessoas e ter um grande fluxo de informações não possuía nenhum tipo de sistema de informações. Todas as solicitações eram feitas verbalmente, via e-mail ou algum tipo de solicitação impressa. Com isso, havia uma grande perda de informações, impossibilitando muitas vezes saber qual a fonte original da informação.

Para facilitar a gestão da informação e a tomada de decisão nos centros de distribuição foi sugerida a implantação de ferramentas de software simples e práticas que garantem a chegada da informação ao destino desejado, de forma completa, otimizando assim os processos envolvidos. Primeiramente foi impantado o software Trello. Para agregar mais valor às informações, o Redmine também foi utilizado. Ambos são softwares livre.

Bastante conhecido em empresas, o Trello é um organizador de tarefas e eventos bastante dinâmico e funcional. Sua organização pode ser feita da maneira desejada, podendo englobar o período inteiro de um projeto. Foi inspirado na metodologia Scrum (uma forma de 
planejar e gerenciar projetos trazendo a autoridade da tomada de decisão a níveis de propriedade de operação e certeza.) que é um processo de desenvolvimento para gerenciar projetos e desenvolvimento ágil de softwares.

O Trello utiliza a essência do Kanban que faz uso de cartões para indicar o andamento dos fluxos de produção. Nesses cartões são colocadas indicações sobre uma determinada tarefa, por exemplo, "para executar", “em andamento" ou "finalizado". O software Trello é basicamente o mesmo processo. Os quadros na tela do usuário indicam o que precisa ser feito (to do), o que está em processamento (in process) e o que foi finalizado (finish). Em todas as etapas os responsáveis pela atividade são identificados permitindo assim saber quem detém a informação em tempo real e quem deu início a mesma. O software foi escolhido dada a sua usabilidade em atender a heterogeneidade no que tange os conhecimentos informáticos do público alvo. Outro ponto favorável é a possibilidade de utilizar a versão mobile e obter a informação com maior flexibilidade.

Assim como o Trello, o Redmine também é um gerenciador de projetos, no entanto, além de acompanhar as atividades o software também disponibiliza um calendário que alerta em quanto tempo resta para que aquela atividade possa ser executada (pois define-se uma data final ao cadastrar uma nova atividade), o percentual concluído e ainda gerar relatórios. Redmine é escrito usando o framework Ruby on Rails. Ele é multiplataforma e suporta diversos Banco de Dados.

Nas organizações, tão importante quanto criar projetos, tarefas e documentações é garantir que tudo isso seja disposto de forma acessível, organizada e padronizada. O padrão ITIL (conjunto de boas práticas para serem aplicadas na infraestrutura, operação e manutenção de serviços de tecnologia da informação) para gerenciamento de serviços e projetos é praticamente perfeito e uma excelente ferramenta que obedece esta biblioteca de Frameworks é o Redmine. O Redmine pode ser implementado em qualquer plataforma de negócio, não se restringindo apenas aos papeis de mercado de TI.

As duas ferramentas foram sugeridas pois apesar de cumprirem a mesma função e um software ser mais completo do que o outro a escolha de apenas um traria prós e contras consideráveis para ambos os lados, por isso a junção dos dois softwares adequava-se melhor para a realidade da empresa. Enquanto o trello é mais intuitivo e acessível até para os menos afeiçoados à informática é uma ferramenta apenas para controle das atividades, sem geração de relatórios e sem datas marcadas visíveis, pode-se dizer que seria um tipo de kanban virtual. 
Já o Redmine é mais completo, com as funções que faltam no Trello, no entanto, menos intuitivo e sua instalação requer noções de informática que não são comuns a todos.

$\mathrm{O}$ questionamento feito quando apresentado o segundo software, foi se haveria perda de informação entre os que optassem por utilizar o Trello e os outros que utilizassem o redmine. Contudo, esta possibilidade já havia sido considerado, assim juntamente com o segundo software um plugin que promove a interação entre os dois softwares foi trazido, fazendo com que as atividades cadastradas no Trello sejam igualmente inseridas no Redmine e vice versa.

\section{ANÁLISE DOS RESULTADOS}

Através das visitas in loco e conversas com os funcionários, pôde-se perceber a quantidade de informações geradas com as demandas do setor pedagógico. Visto que a interação entre os setores atrelados a ele ocorria, como exposto anteriormente, de forma verbal, via-email ou documento impresso, muitas informações eram perdida, prejudicando assim o bom andamento do fluxo natural.

Através do questionário semi estruturado aplicado aos funcionários estes dados foram obtidos de forma empírica tornando possível a visualização como é possível visualizar na figura 1 .

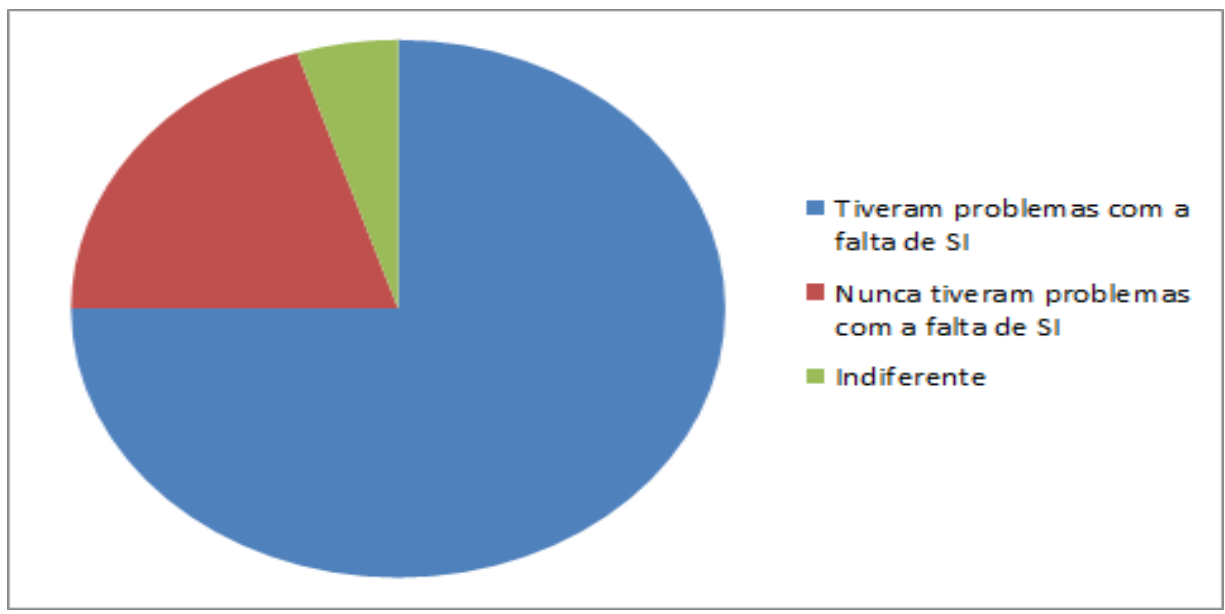

Figura 1 Fase pré implantação do Sistema de Informação Fonte: Dos autores

Através dos dados vimos que a maioria considerável de $75 \%$ dos funcionários considerou que a falta de um SI resultou em problemas em determinado momento, $20 \%$ não considerou a falta de SI um problema e $5 \%$ dos entrevistados foram indiferentes. 
Após a implantação do trello o resultado de satisfação dos funcionários foi esse ilustrado na figura 2.

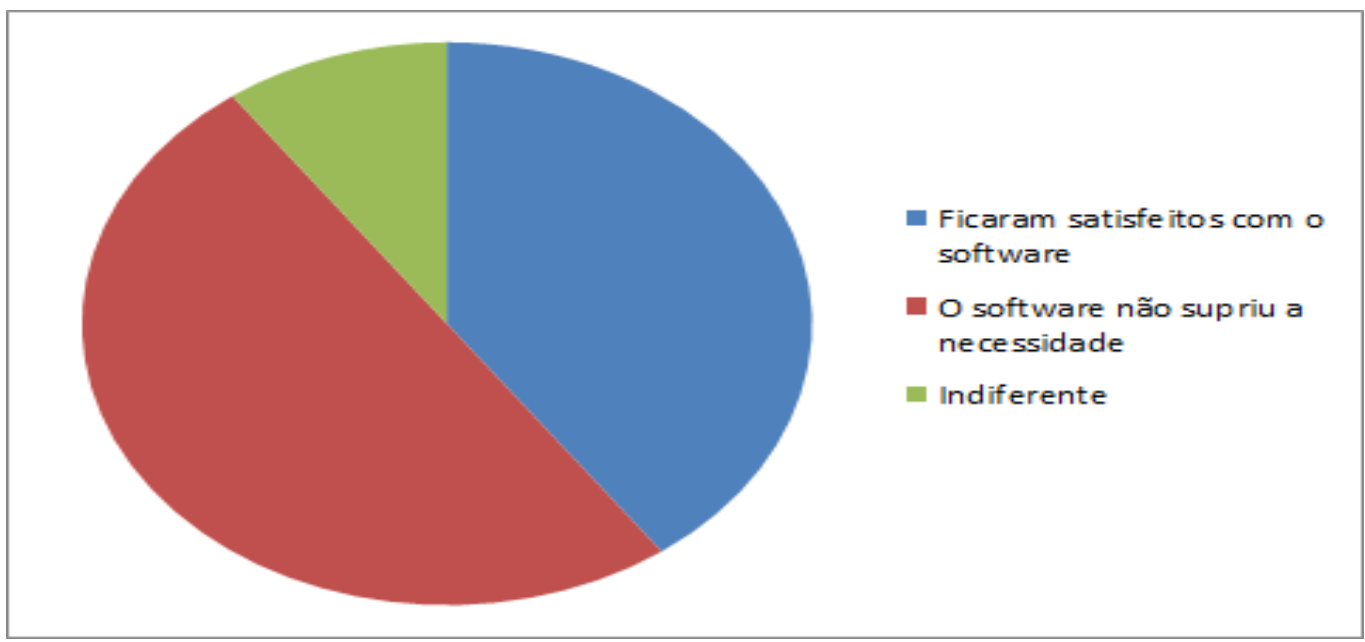

Figura 2 Fase durante a implantação do SI Fonte: Dos autores

Durante a implantação do SI, onde apenas o software Trello foi inserido na realidade da empresa, 50\% considerou o software insuficiente para suprir as necessidades demandadas, $40 \%$ ficou satisfeito com o software e $10 \%$ foi indiferente.

Por fim, foi feita a pesquisa de opinião para saber o percentual que considerou o sistema de informação com os dois softwares integrados satisfatório e o resultado pôde ser observado através do gráfico da figura 3.

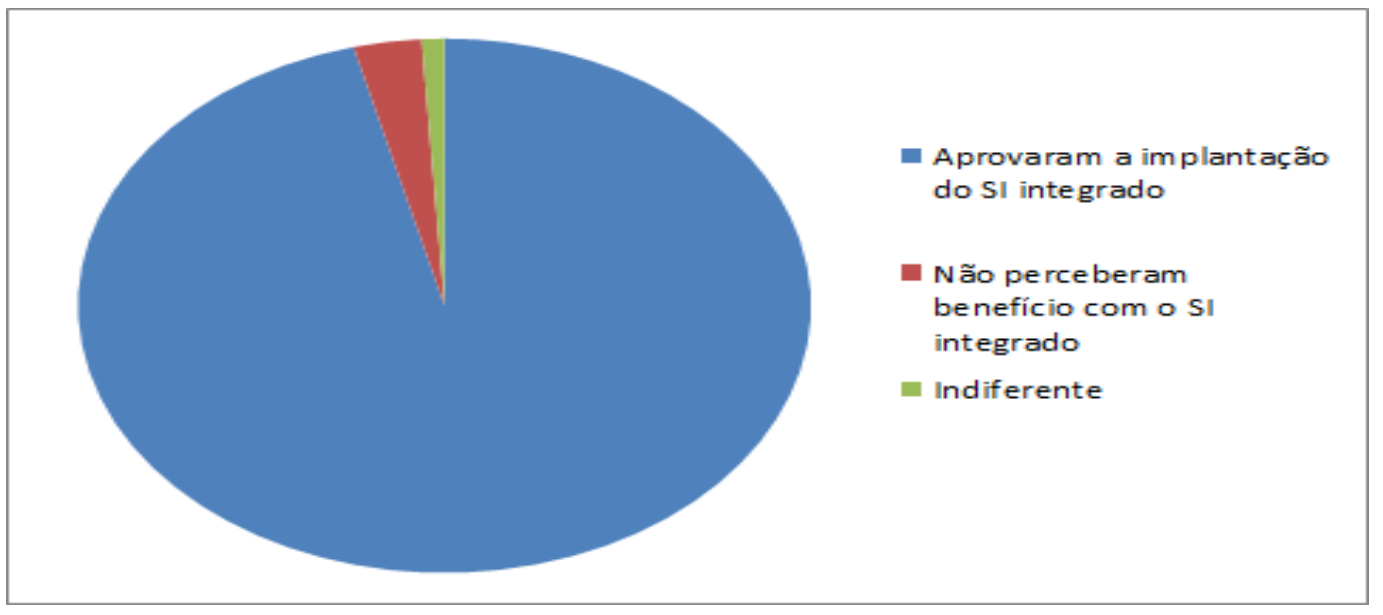

Figura 3 Fase pós implantação do SI

Fonte: Dos autores 
Após a implantação do Sistema de Informação na empresa, 96\% aprovou as novas práticas, $3 \%$ ainda não conseguiu perceber os benefícios e $1 \%$ dos entrevistados foi indiferente as mudanças realizadas. A coordenação do setor pedagógico considerou que após o SI o trabalho tornou-se mais ágil e a repetição de processos foi praticamente anulada, visto que as atividades eram cumpridas tal qual o solicitado o lead time foi reduzido consideravelmente e a interação entre os trabalhadores foi perceptivelmente otimizada.

\section{CONSIDERAÇÕES FINAIS}

A implantação dos sistemas de informação nas organizações é primordial. Trata-se de uma questão de sobrevivência no mercado competitivo. A informação precisa ser útil e acessível, por isso não pode ser centralizada. Na gestão acadêmica o quadro é análogo. Um sistema de informações que permite a integração entre o administrativo e o acadêmico propicia um maior controle sobre desperdícios e melhoria no processo de tomada de decisões em relação a investimentos na área educacional. Com isto a qualidade do serviço prestado se estabelece com naturalidade.

Através do estudo de caso, foi possível perceber empiricamente os benefícios alcançados através do sistema de informação. No que diz respeito a pesquisa, a participação integral dos trabalhadores entrevistados, contribuiu significativamente para a validação deste trabalho.

Procurando um maior aproveitamento dos recursos administrativos proporcionados pela tecnologia da informação, este trabalho visou o desenvolvimento de um Sistema de Informação baseado em gerenciamento de projetos, com a utilização de softwares para auxiliar o colaborador no trabalho, e de forma geral, todos os setores envolvidos com o setor pedagógico do Institudo Metrópole Digital, unidade suplementar da Universidade Federal do Rio Grande do Norte.

\section{REFERÊNCIAS}

ALBERTIN, Alberto Luiz. Aumentando as chances de sucesso no desenvolvimento e implementação de Sistemas de Informação. Revista de Administração de Empresas. São Paulo, v. 36, n. 3. p. 61-69, jul./ago./set. 1996.

CAUTELA, Alciney Lourenço; POLLONI, Enrico Giulio Franco. Sistemas de Informação na administração de empresas. 4. ed. São Paulo: Atlas, 2001. 
CONSELHO DE REITORES DAS UNIVERSIDADES BRASILEIRAS. Seminário Regional. Sistemas de informações gerenciais. Brasília, p. 47-50, 1986.

GIL, A. C. Como elaborar projetos de pesquisa. São Paulo: Atlas, 2002.;

LANZILOTTI, Vivone de Souza. Reengenharia na Universidade: uma interface possível? In:

FINGER, Almeri Paulo. (Org.). Gestão de Universidades: novas abordagens. Curitiba: Champagnat, 1997.

REZENDE, Denis Alcides; ABREU, Aline França de. Tecnologia da informação aplicada a sistemas de informação empresariais: o papel estratégico da informação e dos sistemas de informação nas empresas. 3. ed. São Paulo: Atlas, 2003.

RUBINSZTEJN G., PALACIOS M (2010). El efecto del tiempo en la percepción de la calidad del servicio educativo. Revista Iberoamericana de Educação, $\mathrm{n}^{\circ} .54$, Madrid, OEI. Disponível em: <http://www.rieoei.org/rie54a09.htm>. Acesso em: set. 2014. 